\title{
GLULAM CONNECTIONS ASSEMBLED WITH SCREWS IN DIFFERENT INSTALLATION ANGLES
}

\author{
David Hanna ${ }^{1}$ \\ Thomas Tannert, \\ https://orcid.org/0000-0001-9699-2750
}

\begin{abstract}
Self-tapping screws are the recognized state-of-the-art in fastener technology for timber structures. Combining fasteners of different stiffness, such as self-tapping screws with different installation angles, can be advantageous to simultaneously achieve high connection stiffness and ductility. In this paper, experimental investigations on a total of 65 glued-laminated timber joints assembled with a variety of installation angles including several combinations of self-tapping screws acting axially in withdrawal with self-tapping screws acting laterally are presented. The connection performance was analyzed in terms of the load-carrying capacity, the deformation capacity, the stiffness, and the ductility. The findings demonstrated that joint assemblies with self-tapping screws loaded primarily laterally exhibit low stiffness but high ductility, whereas joint assemblies with self-tapping screws loaded primarily in withdrawal are very stiff but exhibit low ductility. Combining screws in different installation angles created glued-laminated timber connections that combine high stiffness with high ductility. Existing analytical expressions were deemed suitable to estimate load-carrying capacity through simple summation of the different screws' individual resistances.
\end{abstract}

Keywords: Douglas fir, glued-laminated timber, shear connections, self-tapping screws, wood structures.

\section{INTRODUCTION}

With better awareness of its environmental impact, the building industry is increasing the use of more sustainable materials. A favorable strength to weight ratio, a small carbon footprint, and the ease of assembly are drivers for the increased use of engineered wood products (EWPs) in structural applications (Green and Karsh 2012). Elements in timber structures were historically limited in their cross-section and length by the tree size in the surrounding area. The introduction of glued-laminated timber (Glulam) more than a century ago represented a significant technological progress (Dietsch and Tannert 2015). More recent innovations in mass timber products, e.g. Cross-laminated Timber (CLT) (Brandner et al. 2016), novel ductile connections (Loo et al. 2015, Zhang et al. 2018), increased pre-fabrication (Connolly et al. 2018), hybrid design approaches that combine wood with steel or concrete (Yeoh et al. 2011, Dias et al. 2016, Tesfamariam et al. 2014, Zhang et al. 2015), and changes in legislation (NRC 2012, Veilleux et al. 2019) further extended the range of application of timber products in buildings. As a consequence, the design and construction of mass-timber structures is not anymore the domain for early adopters, but is becoming part of regular engineering practice (Tannert et al. 2018).

Self-tapping screws (STS) are the recognized state-of-the-art in fastener technology for timber structures (Dietsch and Brandner 2015); they often do not require pre-drilling, are quick to install, and are therefore cost efficient. STS are produced from hardened steel and exhibit high tensile, yield, and torsional strengths as well as high withdrawal resistance; they can be either partially- (PT) or fully-threaded (FT), with the latter sometimes with a double thread. The thread provides a full mechanical connection along the screw's embedded 
length, which makes STS suited for the reinforcement of timber elements and connections prone to failure due to splitting (Tannert and Lam 2009). Bending of STS, when used as shear connector, can be limited, and the connection stiffness can be increased by an inclined installation (often at $45^{\circ}$ ) to the element interface (Blass and Bejtka 2001).

STS are commonly used in a crossed inclined configuration, where the screws are subjected to combined shear-compression and/or shear-tension stresses (Jockwer et al. 2014, Loss et al. 2018). Previous research on STS studied parameters such as the required spacing (Pirnbacher et al. 2009, Frese et al. 2010), analyzed their lateral and axial stiffness and load-carrying capacity (Tomasi et al. 2010, Ringhofer et al. 2015), the group effect as a function of the number of screws in one connection (Hossain et al. 2019), and their use for seismic applications (Gavric et al. 2015, Hossain et al. 2016). Equations to estimate the STS withdrawal resistance are provided in product approvals and as a generic approach in CEN EN 1995-1-1 (2004). Since the current Canadian Wood Engineering Design standard CSA-O86 (2014) provides no guidance for the application of STS, product approvals such as (CCMC 2018) have to be used in Canada.

Connections combining fasteners with different stiffness: The load transmission to connect timber components can be achieved by means of: i) direct contact between timber members, ii) mechanical fasteners, or iii) adhesive bonding. Besides these three categories, it is conceptually feasible to create a "hybrid" connection (Vallée et al. 2013, Schober and Tannert 2016), e.g. combining an adhesive layer with metal fasteners with the latter considered as back-up for a failing adhesive bond (Hart-Smith 1985). Although the mechanical description of the stress state in hybrid joints is very complicated, there are legitimate rationale for hybrid connections: i) the two methods might achieve the connection for loads coming from different directions; ii) bolts can enhance in the fire resistance of adhesive bonds that carry loads under normal service conditions; and iii) bolts may reduce long-term performance problems of bonded joints (Weitzenboeck and McGeorge 2011). Other examples of hybrid connections are carpentry type joints combined with STS, an adhesive layer, and a combination of both which can lead to significantly increases in strength and stiffness (Tannert 2016) as well as the combination of screws with different angles of installation (Tomasi et al. 2006).

In half-lapped joint CLT test specimens, the performance of connections assembled with STS loaded either primarily laterally (installed at $90^{\circ}$ ) or primarily axially in withdrawal (installed at $45^{\circ}$ ) together with an innovative solution combining these two installation angles was evaluated (Hossain et al. 2018, Sullivan et al. 2018), cf. Figure 1. It was shown that joints with STS loaded primarily laterally exhibited low stiffness but high ductility, whereas joints with STS loaded primarily axially in withdrawal were very stiff but exhibited low ductility. Combining STS of the two installation angles led to connections with high stiffness and high ductility. Research on the seismic performance of mixed angle STS connections between orthogonal CLT plates demonstrated the potential to provide robust connections with increased ductility and displacement capacity (similar to connection with STS loaded laterally) while providing the necessary stiffness and strength (Hossain et al. 2018, Brown et al. 2021).

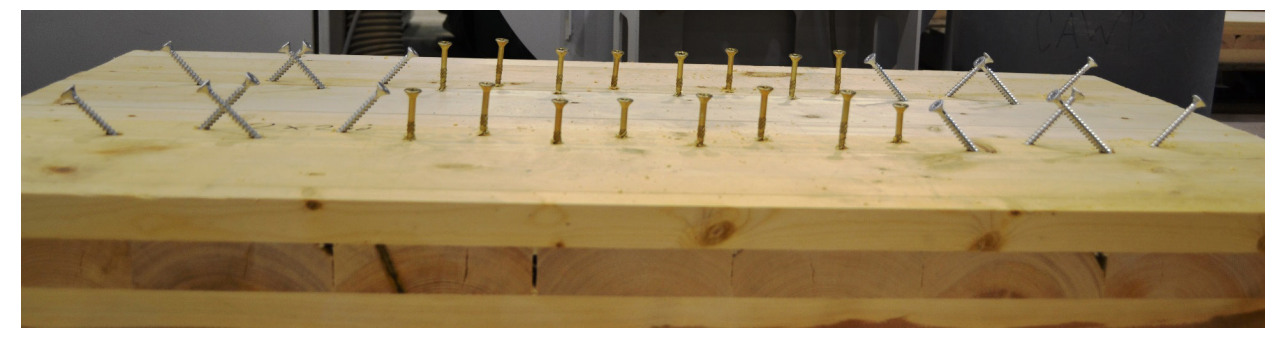

Figure 1: Combination of screws acting laterally with screws acting in withdrawal (Hossain et al. 2018).

Simplified estimates for resistance of STS in timber connections: The lateral resistance of a pair of STS installed symmetrically into equal timber members, $R_{\mathrm{S}}$, can be estimated with Equation 1. Ignoring the contribution of friction, not accounting for the edge effect (Jockwer et al. 2014), and assuming the compressive components of screw in shear-tension and shear-compression are equal and reversed, the lateral resistance of a crossed STS pair loaded in axial-lateral combination, $R_{(S+A), \theta}$, can be estimated with Equation 2. 


$$
\begin{aligned}
& R_{\mathrm{S}}=2\left(R_{\mathrm{V}}+R_{\mathrm{A}} / 4\right) \\
& R_{(\mathrm{S}+\mathrm{A}), \theta}=2\left(R_{\mathrm{v}} \sin \theta+R_{\mathrm{A}} \cos \theta\right)
\end{aligned}
$$

Where $R_{\mathrm{V}}$ is the STS shear resistance, $R_{\mathrm{A}}$ is the STS axial resistance (minimum value of the tensile, head pull-through, and withdrawal resistance $R_{\mathrm{ax}, a, \mathrm{k}}^{\mathrm{A}}$, and is the screw installation to load direction angle.

The lateral and axial withdrawal resistances of STS for $\theta$ between $30^{\circ}$ and $75^{\circ}$ can be linearly added (Blass and Bejtka 2001). Herein, it is postulated that this linear superposition can be applied to joints with a combination of installation angles. As long as the STS slenderness ratio ensures the development of plastic hinges, Equation 3 from CEN EN-1995 (2004) is sufficient to estimate $R_{\mathrm{v}}$. Further, as long as head-pull through and tension failure are avoided, Equation 4 from the STS approval (DIBt 2012) is sufficient to estimate $R_{\mathrm{A}}$ :

$$
\begin{aligned}
& R_{\mathrm{v}}=\sqrt{2 M_{\mathrm{y}} f_{\mathrm{h}, \pm} d_{\mathrm{ef}}} \\
& R_{\mathrm{A}}=R_{\mathrm{ax}, \pm}=k_{\mathrm{ax}} f_{\mathrm{ax}} n_{\mathrm{ef}} d l_{\mathrm{ef}}\left(\frac{\rho_{\mathrm{k}}}{350}\right)^{0,8}
\end{aligned}
$$

Where, $M_{\mathrm{y}}$ is the STS yield moment Nmm, $f_{\mathrm{h}, \alpha}$ is the embedment strength in $\mathrm{N} / \mathrm{mm}^{2}$, see Equation 5 , at an angle to the wood grain $\alpha$ as function of the wood density and the effective screw diameter $d_{\mathrm{ef}}, n_{\mathrm{ef}}$ is the effective number of screws $\left(=n^{0,9}\right), d$ is the outer thread diameter in $\mathrm{mm}, k_{\mathrm{ax}}$ is a reduction factor based on screw installation angle, $f_{\mathrm{ax}}$ is the withdrawal parameter in $\mathrm{N} / \mathrm{mm}^{2}, l_{\text {ef }}$ is the screw's effective withdrawal length (thread minus tip/head length) in $\mathrm{mm}$, and $r_{\mathrm{k}}$ is the characteristic density in $\mathrm{kg} / \mathrm{m}^{3}$.

$$
f_{\mathrm{h}, \pm}=\frac{0,082\left(1-0,01 d_{\mathrm{ef}}\right) \rho_{\mathrm{k}}}{\left(1,35+0,15 d_{\mathrm{ef}}\right) \sin ^{2} \pm+\cos ^{2} \pm}
$$

Previous research on the in-plane shear behaviour of timber joints demonstrated that the use of STS acting primarily laterally together with STS acting primarily axially in withdrawal can lead to stiff connections that are ductile at the same time (Hossain et al. 2018). The mechanical description of the load transfer in joints that combine fasteners with different stiffness is complex and timber design standards do not provide specific provisions. While existing models were deemed inadequate to estimate the stiffness of STS joints in CLT installed with different inclinations and cannot be extended to joints with a combination of installation angles, the existing model to estimate the load-carrying capacity of STS joints were deemed adequate for both shear and axial-lateral loading (Loss et al. 2018).

The primary objective of the research project presented herein was to experimentally investigate the performance of connections between two Glulam members that use a variety of combinations of the installation angle of STS that act primarily laterally and STS that act in axial-lateral combination. The secondary objective was to evaluate whether existing analytical models for the resistance of STS in timber connections can be applied to such assemblies. 


\section{MATERIALS AND METHODS}

\section{Materials}

The connections were tested in Glulam grade Douglas Fir 24f-E with properties as per CSA-O86 (CSA 2014). Beams with a cross section of $80 \mathrm{~mm}$ x $228 \mathrm{~mm}$ were cut to the required dimensions as detailed subsequently. The average moisture content determined using a hand-held resistance moisture meter was 8,4 \%, with a coefficient of variation $(\mathrm{CoV})$ of $12 \%$ and maximum and minimum values of 7,0 \% and 10,9\% respectively. The average apparent density was $556 \mathrm{~kg} / \mathrm{m}^{3}$, which was obtained measuring the weight and dimensions of each test specimen. Heco-Topix ${ }^{\circledR}$-CC STS with nominal and effective core diameters of $d=8,5 \mathrm{~mm}$ and $d$ ef $=8,0 \mathrm{~mm}$, respectively, and with lengths of $150 \mathrm{~mm}, 215 \mathrm{~mm}$, and $300 \mathrm{~mm}$ were used. These STS consists of two threads with different pitches with a central shank, which is beneficial when used as a shear connector since it helps to avoid any gaps between the two timber members to be connected. The screws' European Technical Approval ETA-12/0132 (DIBt 2012) specifies the yield moment as $M_{\mathrm{y}}=23,482 \mathrm{Nmm}$, the characteristic withdrawal parameter as $f_{\mathrm{ax}, \mathrm{k}}=11,8 \mathrm{~N} / \mathrm{mm}^{2}$ and $k_{\mathrm{ax}}=1,0$ for $\alpha>45^{\circ}$ and $=0,77$ for $\alpha>30^{\circ}$. The screw approval (DIBt 2012) was used as a reference for minimum spacing and distances.

\section{Withdrawal tests}

Withdrawal tests were conducted to study the influence of the screw installation angle on the withdrawal resistance. The glulam beams were cut at the desired angles so that the screws were always installed perpendicular to the timber surface for ease of testing. An example of a specimen with a $60^{\circ}$ orientation is shown in Figure 2 a. Five different installation angles $\left(90^{\circ}, 75^{\circ}, 60^{\circ}, 45^{\circ}\right.$, and $\left.30^{\circ}\right)$ between the wood grain and the screw axis were investigated, with ten replicates each.

The $70 \mathrm{~mm}$ thick glulam block was resting on a $5 \mathrm{~mm}$ thick piece of wood to allow clearance for the tip of the screw, cf. Figure 2c. Two HSS steel profiles were used to clamp down the Glulam, further the L-shaped profiles helped avoid wood splitting and obtain results that reflected the withdrawal resistance. The tests were performed using a universal test machine (UTM) with a calibrated load cell at a loading rate of $2 \mathrm{~mm} / \mathrm{min}$.
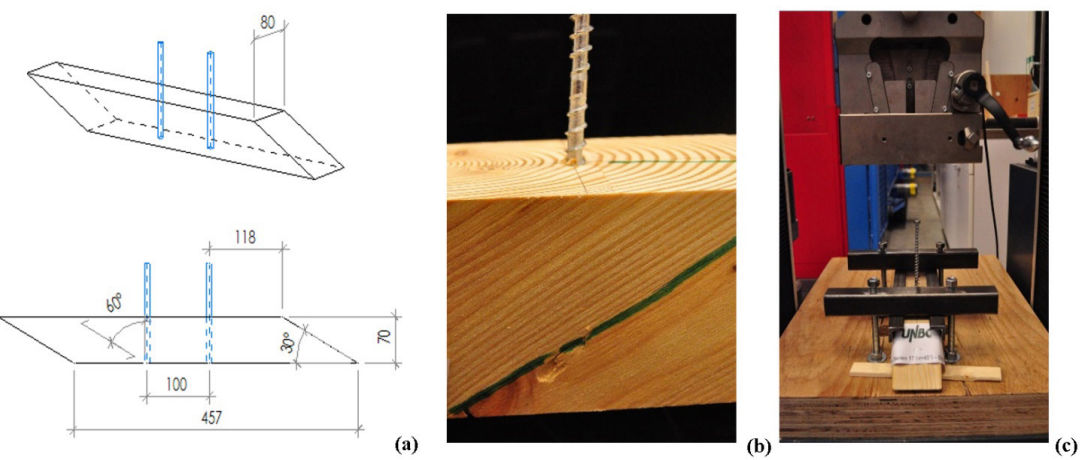

Figure 2: (a) Specimen layout for the withdrawal at $60^{\circ}$, (b) photo and (c) test set-up.

The average experimental withdrawal parameters, $f_{\text {mean }}$, are illustrated in Figure 3 together with their $5^{\text {th }}$ percentile values, $f_{5 \%}$, calculated using Equation 6 assuming a normal distribution:

$$
f_{5 \%}=f_{\text {mean }} \exp \left(-\left(2,645+\frac{1}{\sqrt{n}}\right) \operatorname{CoV}(x)+0,15\right)
$$

The results showed an almost constant withdrawal resistance, independent of installation angle. The $5^{\text {th }}$ percentile parameter as a proxy for the characteristic withdrawal resistance was always around $8 \mathrm{~N} / \mathrm{mm}^{2}$ and therefore lower than the specified characteristic withdrawal parameter (DIBt 2012). This difference can be partially explained by the lack of adjustments for the apparent density determined at $8 \%$ moisture content into 
a characteristic oven-dry density.

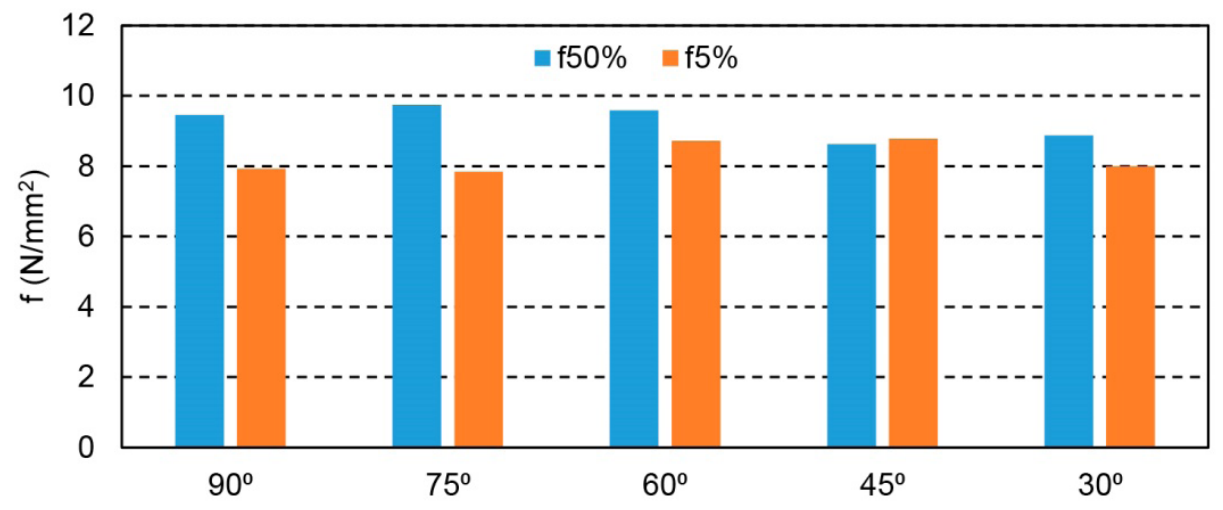

Figure 3: Screw withdrawal parameter as function of installation angle.

\section{Connection specimen description}

Thirteen test series, labelled S1-S13, with different screw configurations were designed, cf. Table 1 and Figure 4. Five replicates were assembled and subsequently tested for each series for a total of 65 tests. Each specimen was $550 \mathrm{~mm}$ high, $146 \mathrm{~mm}$ wide, and $80 \mathrm{~mm}$ deep, with a single shear plane as joint between the two Glulam members. In each joint, four screws were installed with varying the angle between screw axis and shear plane. Different screw lengths were used based on the joint configuration. The screws were always installed (countersunk) in such a way that their centres of embedment length $\left(l_{\mathrm{ef}}\right)$ were right at the joint line between the two Glulam members. For all specimens, a spacing parallel to the grain of $50 \mathrm{~mm}$ was used. To avoid interference between inclined screws, two rows of screws with a spacing across the grain of $20 \mathrm{~mm}$ were used. The minimum required edge and side distances according to the product approval (DIBt 2012) were met or exceeded in all configurations.

Table 1: Test series overview.

\begin{tabular}{|c|c|c|c|}
\hline & STS \# & $l_{\mathrm{ef}}(\mathrm{mm})$ & Resistance estimate \\
\hline $\mathrm{S} 1$ & $4 @ 90^{\circ}$ & 70 & $4 R_{\mathrm{s}}$ \\
\hline $\mathrm{S} 2$ & $4^{\mathrm{X}} @ 75^{\circ}$ & 70 & $4 R_{(\mathrm{S}+\mathrm{A}), 75}$ \\
\hline S3 & $4^{\mathrm{X}} @ 60^{\circ}$ & 70 & $4 R_{(\mathrm{S}+\mathrm{A}), 60}$ \\
\hline S4 & $4^{\mathrm{X}} @ 45^{\circ}$ & 70 & $4 R_{(\mathrm{S}+\mathrm{A}), 45}$ \\
\hline S5 & $4 @ 45^{\circ}$ & 70 & $4 R_{(\mathrm{S}+\mathrm{A}), 45}$ \\
\hline S6 & $4^{\mathrm{X}} @ 45^{\circ}$ & 100 & $4 R_{(\mathrm{S}+\mathrm{A}), 45}$ \\
\hline S7 & $4^{\mathrm{X}} @ 30^{\circ}$ & 70 & $4 R_{(\mathrm{S}+\mathrm{A}), 30}$ \\
\hline S8 & $2 @ 90^{\circ}+2^{X} @ 60^{\circ}$ & $70+70$ & $2 R_{\mathrm{S}}+2 R_{(\mathrm{S}+\mathrm{A}), 60}$ \\
\hline S9 & $2 @ 90^{\circ}+2^{x} @ 45^{\circ}$ & $70+100$ & $2 R_{\mathrm{S}}+2 R_{(\mathrm{S}+\mathrm{A}), 45}$ \\
\hline $\mathrm{S} 10$ & $2 @ 90^{\circ}+2 @ 45^{\circ}$ & $70+100$ & $2 R_{\mathrm{S}}+2 R_{(\mathrm{S}+\mathrm{A}), 45}$ \\
\hline S11 & $2 @ 90^{\circ}+2^{x} @ 30^{\circ}$ & $70+145$ & $2 R_{\mathrm{S}}+2 R_{(\mathrm{S}+\mathrm{A}), 30}$ \\
\hline $\mathrm{S} 12$ & $2^{\mathrm{x}} @ 75^{\circ}+2^{\mathrm{x}} @ 45^{\circ}$ & $70+100$ & $2 R_{(\mathrm{S}+\mathrm{A}), 75}+2 R_{(\mathrm{S}+\mathrm{A}), 45}$ \\
\hline $\mathrm{S} 13$ & $2^{x} @ 75^{\circ}+2^{x} @ 30^{\circ}$ & $70+145$ & $2 R_{(\mathrm{S}+\mathrm{A}), 75}+2 R_{(\mathrm{S}+\mathrm{A}), 30}$ \\
\hline
\end{tabular}

Series S1-S7 exhibited a single screw installation angle $\theta$ of between $90^{\circ}(\mathrm{S} 1)$ and $30^{\circ}(\mathrm{S} 7)$. Three variants of the $45^{\circ}$ degree orientation were tested: (S5) with all four screws loaded in shear-tension, and (S4 and S6) with two pairs of crossed screws where two screws are loaded in shear-tension and the other two in shear compression. The difference between these latter two series was the screw embedment length $l_{\text {ef }}$ ( $70 \mathrm{~mm}$ for S4 and $102 \mathrm{~mm}$ for S6). Series S8-S13 exhibited a combination of screw installation angles, e.g. a combination of $90^{\circ}$ and $45^{\circ}$ (S8 and S9) or a combination of $75^{\circ}$ and $30^{\circ}$ (S13). The proposed method to estimate connection load-carrying capacity is included in Table 1 . 


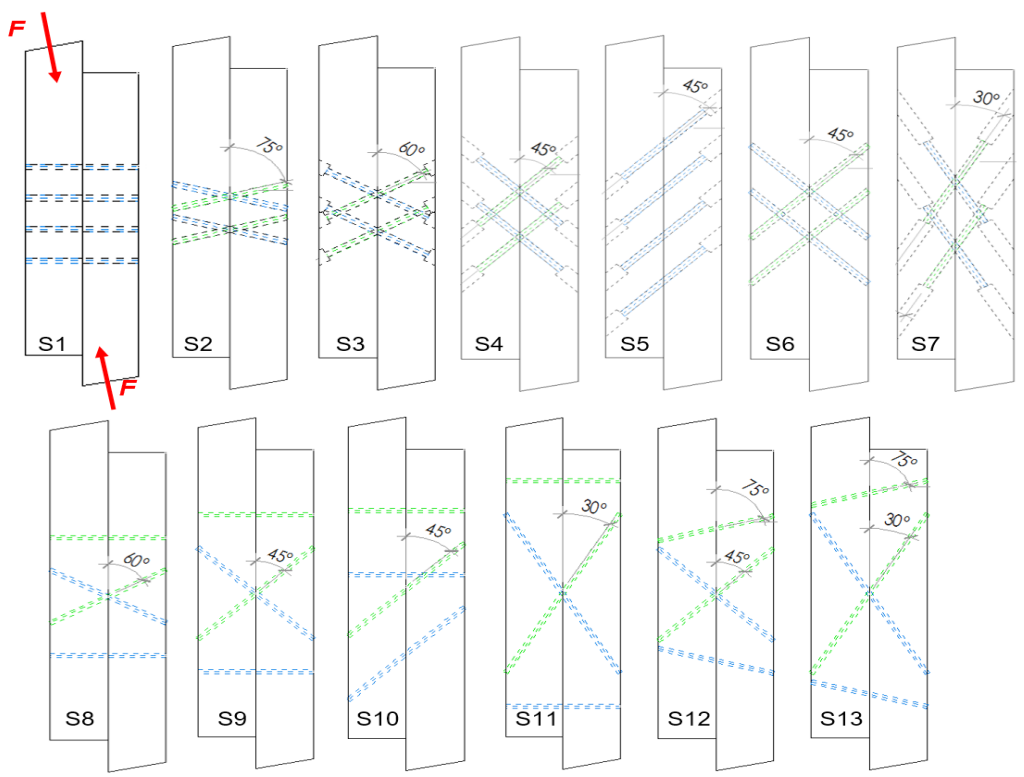

Figure 4: Specimen configuration for all test series.

\section{Test methods}

Test specimens were rotated $12^{\circ}$ similar to the procedure suggested in CEN EN-408 (2012) so that the resultant force between loading and support were aligned, cf. Figure 5a. The angle was the consequence of the specimen height. All test presented results are the components of the load parallel to the shear planes. The loads were applied according to CEN EN-26891 (1991) at a displacement controlled loading rate of $3 \mathrm{~mm} / \mathrm{min}$ and $10 \mathrm{~mm} / \mathrm{min}$ for the test series that exhibited brittle and ductile behaviours, respectively. Specimens were loaded to $40 \%$ of the estimated capacity, then unloaded to $10 \%$ of estimated capacity, and finally loaded to failure, with failure defined as the point when load dropped to $80 \%$ of the maximum. The actuator load and the relative displacements between the two members using two calibrated potentiometers (one on the frontside and one on the back-side) which were attached to the Glulam specimens at mid-height were recorded at a rate of $10 \mathrm{~Hz}$. The displacements reported herein are the average values between the measurements at the front- and the back-side.
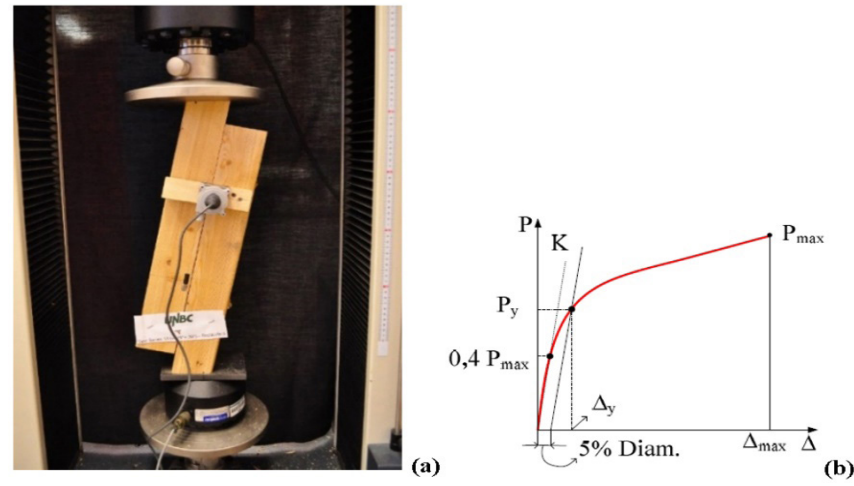

Figure 5: (a) Test set-up and (b) determination of yield point. 


\section{Analyses}

The impact of the screw installation angle on connection performance was analysed looking at the yield load $F_{\mathrm{Y}}$, maximum load $F_{\max }$, displacement at yield load $d_{\mathrm{Y}}$, displacement at maximum load $d_{\mathrm{Fmax}}$ stiffness $k$, and ductility $\mu$. While $F_{\max }$ and $d_{\mathrm{Y}}$ were determined directly from the load-displacement curves, $k$ was computed for the range between $10 \%$ and $40 \%$ of $F_{\max }$ as per CEN EN-26891 (1991). To identify $F_{\mathrm{Y}}$ and $d_{\mathrm{Y}}$, the 5 $\%$-diameter offset method (Muñoz et al. 2008), that requires a straight line with a slope equal to the initial stiffness and an offset on the relative displacement axis equal to $5 \%$ of the diameter of the fastener, was applied, cf. Figure $5 \mathrm{~b}$. Ductility is often computed as ratio between ultimate displacement and $d_{\mathrm{Y}}-$ a metric that does not properly account for the different load-deformation behaviour and does not allow for valid comparisons between test series. Therefore, herein $\mu$ was computed as the ratio between $d_{\mathrm{Fmax}}$ and $d_{\mathrm{Y}^{*}}$ An established scale was used to characterize ductility as brittle for $\mu \leq 2$; low ductility for $2<\mu \leq 4$; moderate ductility for $4<\mu \leq$ 6 , and high ductility for $\mu>6$ (Smith et al. 2006). For an in-depth discussion on ductility, the reader is kindly referred to Piazza et al. 2011.

\section{RESULTS AND DISCUSSION}

Figure 6 presents a typical load-deformation curve from each test series with one screw installation angle (S1-S7) and Figure 7 presents a typical load-deformation curve from each test series that combined two different screw installation angle (S8-S13). For clarity, the initial loading up to $40 \%$ of capacity is not plotted. As can be observed from Figure 6, large differences existed between the individual series as a function of the screw installation angle. The lower bound for stiffness and load-carrying capacity, yet exhibiting the largest deformation capacity, was exhibited by series S1 which used screws installed at $90^{\circ}$, acting primarily laterally. The upper bound for stiffness and load-carrying capacity, yet with low ductility was obtained for series S5 which used long screws installed at $45^{\circ}$, acting primarily in withdrawal. Similar to the test series with one screw installation angle, large differences existed between the individual series, cf. Figure 7 . But in contrast to the former, the latter test series achieved both high stiffness and large deformation capacity. The lower bound for stiffness and load-carrying capacity, yet exhibiting the largest deformation capacity, was exhibited by series S8 which combined screws installed at $90^{\circ}$ and $60^{\circ}$. The upper bound for stiffness and load-carrying capacity, yet with low ductility was obtained for series S11 which combined screws installed at $90^{\circ}$ and $30^{\circ}$. Series S10 and S13.

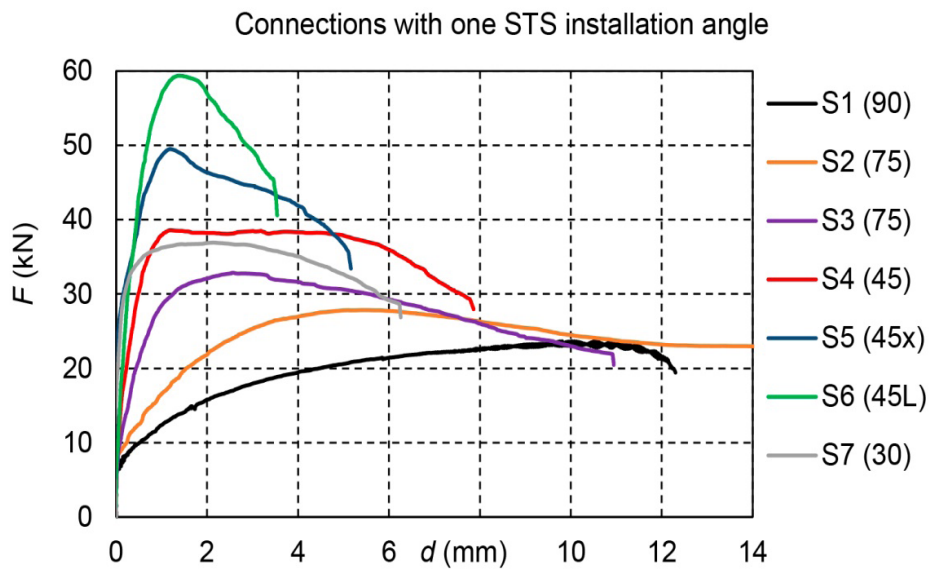

Figure 6: Typical load-deformation curves from test series S1-S7. 
Connections with two STS installation angles

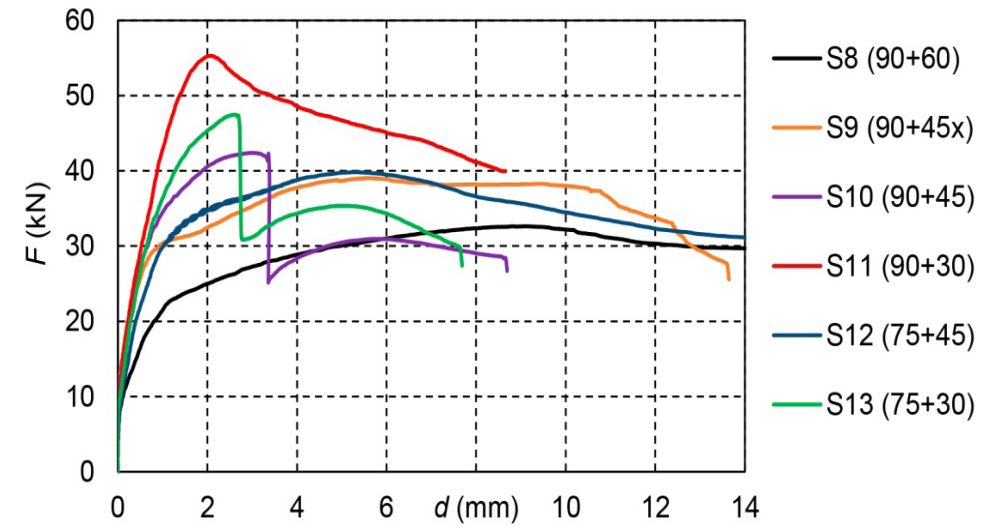

Figure 7: Typical load-deformation curves from test series S8-S13.

The average of each test series results for the load carrying capacity $F_{\max }$, displacement at maximum load $d_{\text {Fmax }}$, yield load $F_{\mathrm{Y}}$, stiffness $k$; and ductility $\mu$, as well as the respective CoVs for each test series are summarized in Table 2 and illustrated in Figure 8.

Table 2: Results summary.

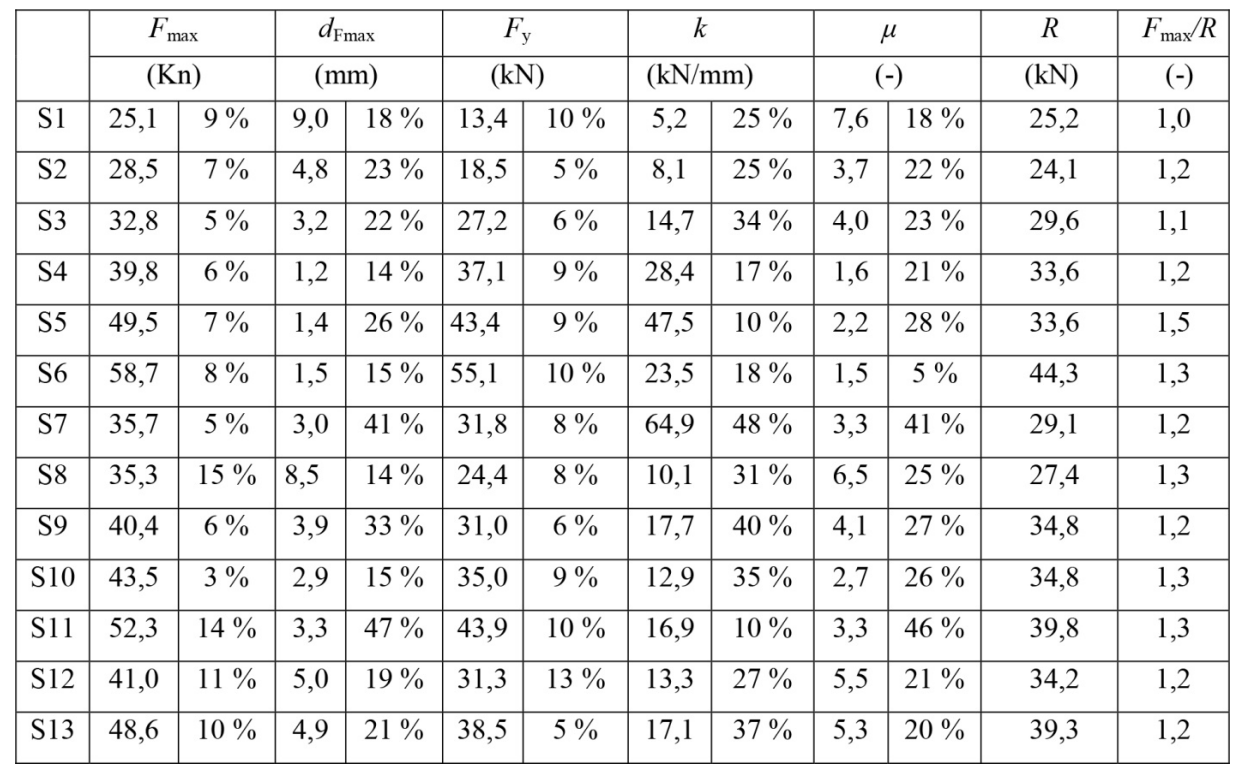

The load carrying capacity increases with a decrease in installation angle from $25 \mathrm{kN}$ for S1 with screws installed at $90^{\circ}$ to $40 \mathrm{kN}$ for $\mathrm{S} 4$ with screws installed at $45^{\circ}$, cf. Figure $8 \mathrm{a}$. Interestingly, it dropped to $36 \mathrm{kN}$ for $\mathrm{S} 7$ with screws installed at $30^{\circ}$, possibly because less friction was activated. When comparing the series with $45^{\circ}$ degree screws, there was an approximately proportionate load-carrying capacity increase with increased embedment length from S4 (40 kN for $70 \mathrm{~mm})$ to S6 $(59 \mathrm{kN}$ for $100 \mathrm{~mm})$ and a $25 \%$ increase when installing all screws in such a way that they act in shear-tension ( 55 with $50 \mathrm{kN}$ ). The same trends can be observed when combining screws at different angles (S8-S13). Variability within tests series was on average $8 \%$ with a maximum of $14 \%$ for S8 and a minimum of $3 \%$ for S11. 
The differences in displacement capacity between the individual tests series were much more pronounced with $d_{\mathrm{Fmax}}$ decreasing significantly with smaller installation angles: from 9,0 $\mathrm{mm}$ for $\mathrm{S} 1$ to $1,2 \mathrm{~mm}$ for S4, cf. Figure $8 \mathrm{~b}$. Again, $\mathrm{S} 7$ with screws installed at $30^{\circ}$ was exhibiting a behaviour against this trend with $d_{\text {Fmax }}=3,0$ $\mathrm{mm}$. When comparing the different series with $45^{\circ}$ screws, only very small differences were observed with 1,5 $\mathrm{mm}$ and 1,4 $\mathrm{mm}$ for S5 and S6, respectively. The series which combined screws at different angles (S8-S13) reached displacement capacities between 2,9 $\mathrm{mm}$ and 5,0 $\mathrm{mm}$. Only S8, which combined screws at $90^{\circ}$ and $60^{\circ}$ showed a different behaviour with $d_{\text {Fmax }}=12,5 \mathrm{~mm}$. Variability within the test series was on average $26 \%$ with a maximum of $68 \%$ for S8 and a minimum of $12 \%$ for S4.

Connection stiffness followed a clear trend with increasing $k$ for decreasing installation angle, i.e. from $4,5 \mathrm{kN} / \mathrm{mm}$ for S1 to $67 \mathrm{kN} / \mathrm{mm}$ for S7 (screws installed at $30^{\circ}$ ), cf. Figure $8 \mathrm{c}$. When comparing the different series with $45^{\circ}$-degree screws, a large increase was observed when installing all screws to act in shear-tension (S5 with $41 \mathrm{kN} / \mathrm{mm}$ ). The series combining screws at different angles (S8-S13) exhibited stiffness of between $10 \mathrm{kN} / \mathrm{mm}$ and $30 \mathrm{kN} / \mathrm{mm}$ for S8 and S13, respectively. No clear correlation between the single screw stiffness results and the test series with a single screw installation angles or test series with a combination of screw installation angles could be established. Variability within the test series was very large was on average $49 \%$ with a maximum of $98 \%$ for S12 and a minimum of $15 \%$ for S4.

The test series ductility followed a very similar trend as the deformation capacities with $\mu$ decreasing significantly with a decrease in installation angle from $\mu>6$ (ductile) for S1 to $\mu=1,5$ (brittle) for S4, cf. Figure $8 \mathrm{~d}$. Again, S7 with STS at $30^{\circ}$ exhibited a behaviour against this trend with $\mu=4,4$ (moderately ductile). When comparing the different series with $45^{\circ}$ screws, while there were some differences, all exhibited brittle behaviour with $\mu<2,0$. The series combining screws at different angles achieved at least low or moderately ductile behaviour (S9-S13) while S8 combining screws at $90^{\circ}$ and $60^{\circ}$ was ductile with $\mu>2,0$. Variability within the individual tests series was on average $25 \%$ with a maximum of $50 \%$ for S7 and a minimum of $5 \%$ for S5.
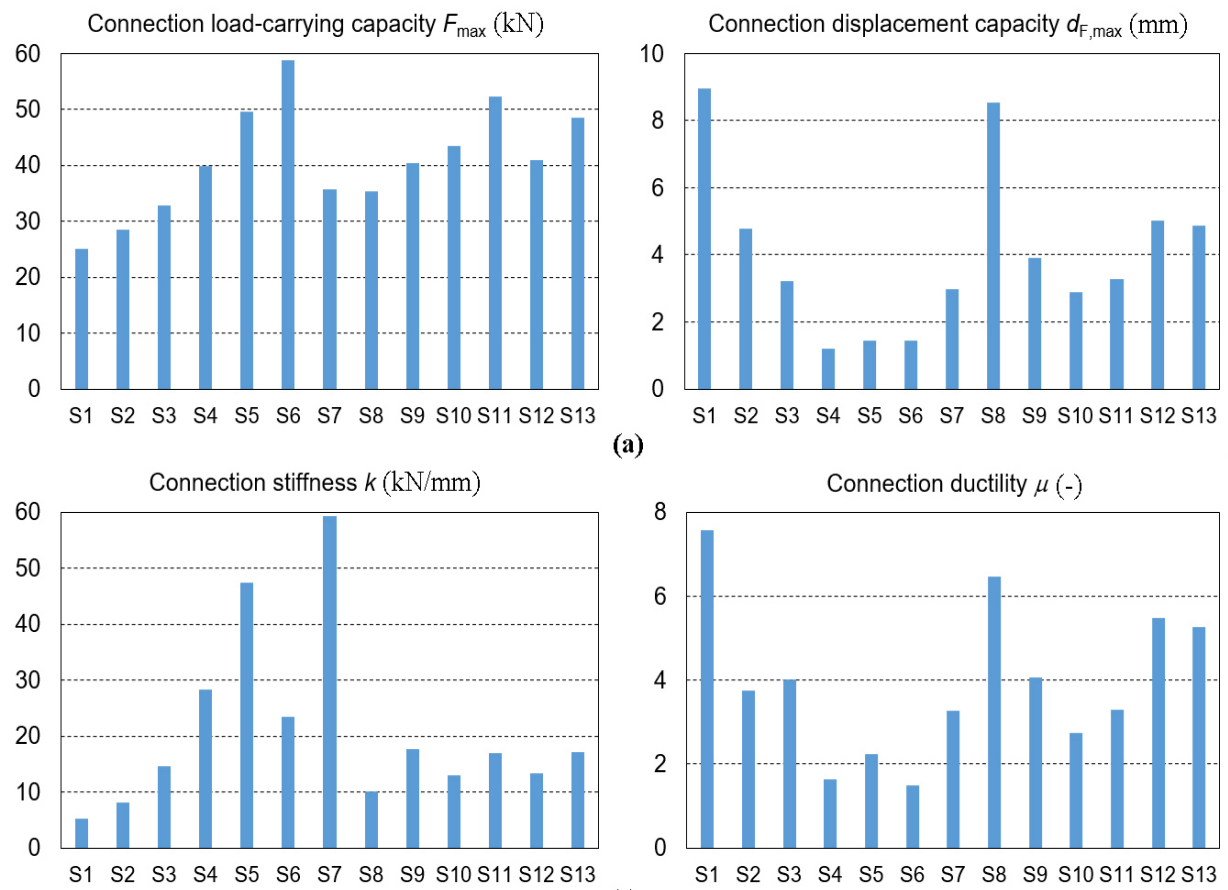

(a)

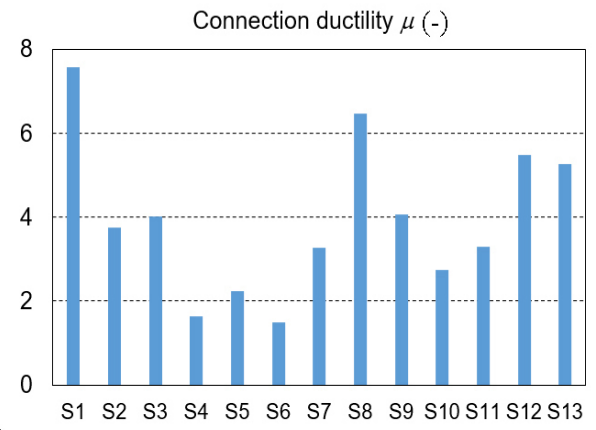

(c)

Figure 8: Detailed comparison between test series: (a) $\mathrm{F}_{\max }$; (b) $\mathrm{d}_{F \max }$; (c) $\mathrm{k}$; and (d) $\mu$. 
The failure modes of the different test series are illustrated in Figure 9. In series S1, the screws failed due to a combination of wood embedment and plastic hinge at the joint interface. While the screws in series S2 (installed at $75^{\circ}$ ) showed a combination of developing a plastic hinge combined with withdrawal from the Glulam members, the screws installed at $60^{\circ}$ and $45^{\circ}$ (S3 and S6) showed full withdrawal failure. In series S4, the two shear-compression screws (left-hand side of photo) developed two plastic hinges due to buckling, while the two shear-tension screws (right-hand side of photo) remained straight and failed in withdrawal. The same failure mode was observed for all four screws of series S5. Failure of the screws in those series that combined different installation angles (S8-S13) was characterized by a combination of the aforementioned failure modes. In all cross-installed configurations, the screw in shear-compression developed a plastic hinge due to buckling, while the screw in shear-tension failed only in withdrawal and the screws installed at $90^{\circ}$ failed due to a combination of wood embedment and plastic hinge at the joint interface.
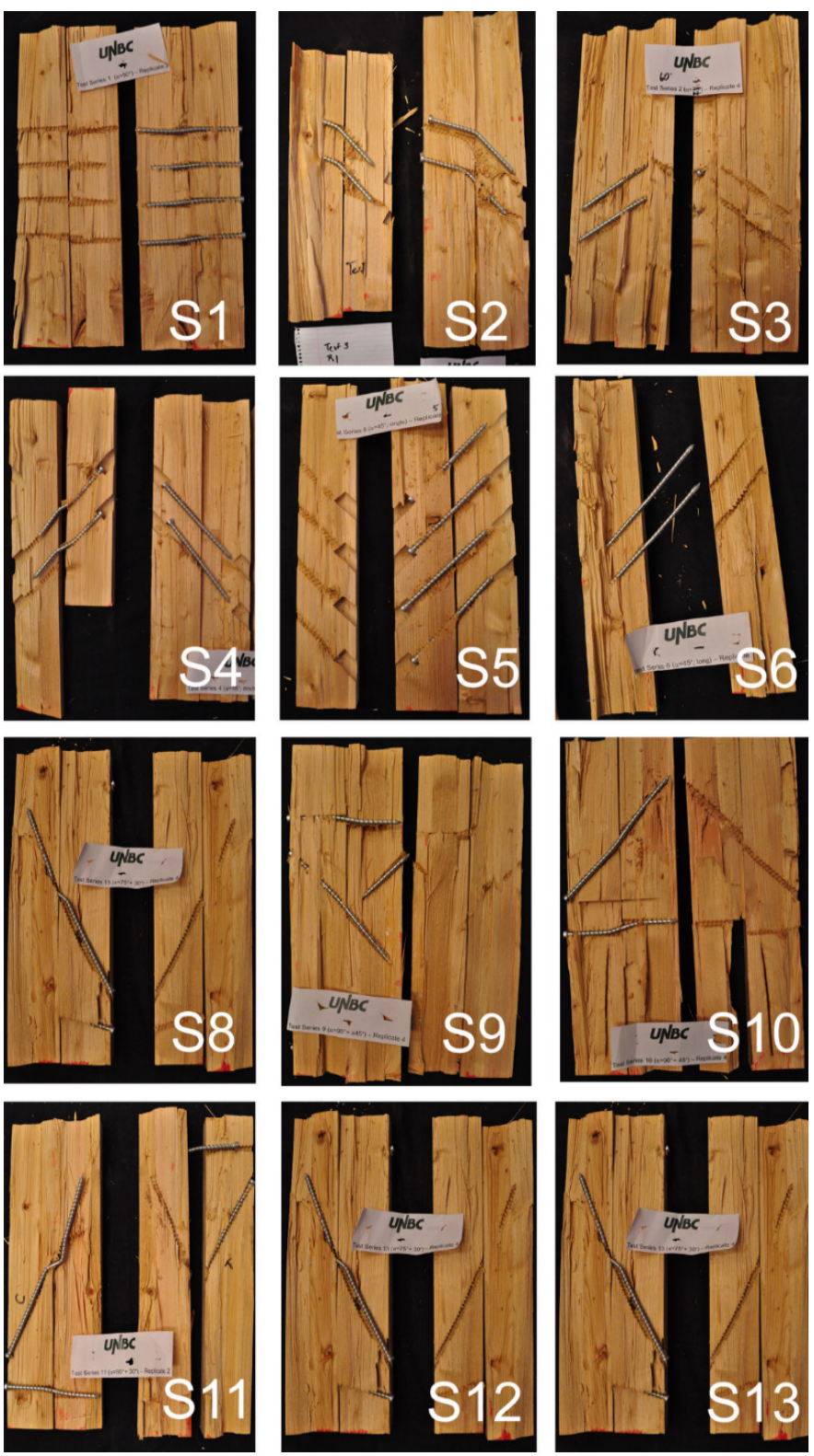

Figure 9: Photos of typical failure modes of specimens after testing. 
Equation 1, Equation 2, Equation 3, Equation 4 and Equation 5 were used to estimate the predicted mean load-carrying capacities $R$ computed using Equation 3 and Equation 4 of the Glulam connections applying the parameters listed in Table 1 . The ratio between the experimentally obtained capacity and predicted load carrying capacity $F_{\max } / R$ is provided in Table 2 . As the primary objective of this research was to investigate the performance of Glulam joint using STS installed with a combination of angles and not to develop new predictive models, it was deemed sufficient to present the ratios between experimental averages and the predictions using the average density. For laterally loaded screws, the ratio $F_{\max } / R_{\mathrm{A}}$ was 1,0 which indicated that the established model for laterally loaded screws was very accurate. For axially-laterally loaded screws, the $F_{\max } / R_{\mathrm{A}}$ ranged between 1,1 and 1,5, and with an average value of 1,2 which confirmed that the simplified load-carrying capacity model was also quite accurate. The largest under-prediction occurred for series S5 where all screws were loaded in shear-tension, which indicated that neglecting the frictional component is overly conservative.

\section{CONCLUSIONS}

Experimental investigations were conducted on a total of 65 Glulam connections assembled with a variety of installation angles including several combinations of STS acting primarily laterally (installed at $90^{\circ}$ ) with STS loaded axially-laterally (installed at angles between $75^{\circ}$ and $30^{\circ}$ ). The connection performance was analysed in terms of load-carrying capacity, deformation capacity, stiffness, and ductility. The analysis presented herein allow to draw the following conclusions:

Using STS installed at $90^{\circ}$ (series S1) lead to ductile connections that reach large displacements before failing. Such joint assemblies are appropriate for applications that require energy dissipation.

Using STS that are loaded primarily in withdrawal (series S2 - S7) lead to significantly stiffer joints assemblies; however, these assemblies exhibit low ductility and low deformation capacity.

The combination of STS installed at different angles creates assemblies that exhibit both reasonably high stiffness and at least moderate ductility.

The existing analytical models are adequate to estimate the load-carrying capacity of screw assemblies with different installation angles.

A simple superposition of the estimated load-carrying capacity of connections combining screws of two different screw installation angles leads to acceptable estimates.

\section{ACKNOWLEDGEMENTS}

This research was supported by the British Columbia Innovation Council through funding to the $\mathrm{BC}$ Leadership Chair in Tall Wood and Hybrid Structures Engineering. The laboratory support provided by Michael Billups and Maik Gehloff is greatly appreciated. 


\section{REFERENCES}

Blass, H.J.; Bejtka, I. 2001. Screws with continuous threads in timber connections. In Proceedings of RILEM Symposium on Joints in Timber Structures. Stuttgart, Germany.

Brandner, R.; Flatscher, G.; Ringhofer, A.; Thiel, A. 2016. Cross Laminated Timber (CLT): Overview and Development. European Journal of Wood and Wood Products 74(3): 331-351. https://doi.org/10.1007/ s00107-015-0999-5

Brown, J.; Li, M.; Tannert, T.; Moroder, D. 2021. Experimental Study on Orthogonal Joints in Cross-Laminated Timber with Self-Tapping Screws installed with Mixed Angles. Eng Struct 228: 111560. https://doi.org/10.1016/j.engstruct.2020.111560

CCMC. 2018. Evaluation report ASSY® VG plus and SWG ASSY® 3.0 Self-tapping wood screws. CCMC. 13677-R. 2018. CNational Research Council of Canada: Ottawa, Canada. ISSN 1206-1220. https:/www.swg-produktion.de/fileadmin/swg-produktion.de/Media/10_Zertifizierung/CCMC_13677-R_revised_2020-01-30_bis_11-2022_.pdf

CSA. 2014. CSA-O86 Engineering Design in Wood. Mississauga, Canada. https://cwc.ca/how-to-buildwith-wood/codes-standards/wood-standards/csa-o86-engineering-design-in-wood/

Connolly, T.; Loss, C.; Iqbal, A.; Tannert, T. 2018. Feasibility Study of Mass-Timber Cores for the UBC Tall Wood Building. Build 8(8): 98. https://doi.org/10.3390/buildings8080098

CEN. 1991. EN-26891: Timber structures - joints made with mechanical fasteners, general principles for the determination of strength and deformation characteristics. Brussels, Belgium.

CEN. 2004. EN 1995-1-1: Eurocode 5 - Design of Timber Structures - Part1-1: General-Common rules and rules for buildings. Brussels, Belgium.

CEN. 2012. EN 408: Timber structures-Structural timber and glued laminated timber-Determination of some physical and mechanical properties. Brussels, Belgium.

DIBt. 2012. ETA-12/0132 Heco-Topix $®-T$ and Heco-Topix ${ }^{\circledR}-C C$ screws for use in timber constructions. European Technical Approval. Berlin, Germany.

Dias, A.; Skinner, J.; Crews, K.; Tannert, T. 2016. Timber-concrete-composites increasing the use of timber in construction. European Journal of Wood and Wood Products 74(3): 443-451. https://doi.org/10.1007/ s00107-015-0975-0

Dietsch, P.; Brandner, R. 2015. Self-tapping screws and threaded rods as reinforcement for structural timber elements - A state-of-the-art report. Constr Build Mater 97: 78-89. https://doi.org/10.1016/j.conbuildmat.2015.04.028

Dietsch, P.; Tannert, T. 2015. Assessing the integrity of glued-laminated timber elements. Constr Build Mater 101(2): 1259-1270.

Frese, M.; Fellmoser, P.; Blass, H.J. 2010. Models for the calculation of the withdrawal capacity of self-tapping screws. European Journal of Wood and Wood Products 68(4): 373-384. https://doi.org/10.1007/ s00107-009-0378-1

Gavric, I.; Fragiacomo, M.; Ceccotti, A. 2015. Cyclic behaviour of typical screwed connections for cross-laminated structures. European Journal of Wood and Wood Products 73(2): 179-191. https://doi.org/10.1007/s00107-014-0877-6

Green, M.C.; Karsh, J.E. 2012. Tall Wood - The Case for Tall Wood Buildings. Wood Enterprise Coalition: Vancouver, Canada.

Hart-Smith, L.J. 1985. Bonded-bolted composite joints. J Aircraft 22: 993-1000. https://arc.aiaa.org/doi/ abs/10.2514/3.45237

Hossain, A.; Danzig, I.; Tannert, T. 2016. Cross-laminated timber shear connection with innovative self-tapping screw assemblies. J Struct Eng-ASCE 142(11): 04016099.

Hossain, A.; Popovski, M.; Tannert, T. 2018. Cross-laminated timber connections assembled with a combination of screws in withdrawal and screws in shear. Eng Struct 168: 1-11. https://doi.org/10.1061/ (ASCE)ST.1943-541X.0001572 
Hossain, A.; Popovski, M.; Tannert, T. 2019. Group Effects for Shear Connections with Self-Tapping Screws in CLT. JStruct Eng-ASCE 142(11): 04019068. https://doi.org/10.1061/(ASCE)ST.1943-541X.0002357

Jockwer, R.; Steiger, R.; Frangi, A. 2014. Design model for inclined screws under varying load to grain angles. In Proceedings of International Network on Timber Engineering Research. Bath, United Kingdom.

Loo, W.Y.; Quenneville, P.; Chouw, N. 2015. A low damage and ductile rocking timber wall with passive energy dissipation devices. Earthquake and Structures 9(1): 127-143. http://dx.doi.org/10.12989/ eas.2015.9.1.127

Loss, C.; Hossain, A.; Tannert, T. 2018. Simple cross-laminated timber shear connections with spatially arranged screws. Eng Struct 173: 340-356. https://doi.org/10.1016/j.engstruct.2018.07.004

Muñoz, W.; Mohammad, M.; Salenikovich, A.; Quenneville, P. 2008. Need for a harmonized approach for calculations of ductility of timber assemblies. In Proceedings of CIB Working Commission W18 - Timber, St. Andrews, Canada.

NRC. 2012. Building Code of British Columbia. Victoria, Canada.

Piazza, M.; Polastri, A.; Tomasi, R. 2011. Ductility of Timber Joints under Static and Cyclic Loads. In Proceedings of the Institution of Civil Engineers - Structures and Buildings 164(2): 79-90. https://doi.org/10.1680/stbu.10.00017

Pirnbacher, G.; Brandner, R.; Schickhofer, G. 2009. Base parameters of self-tapping screws. In Proceedings of CIB Working Commission W18 - Timber Structures. Dübendorf, Switzerland.

Ringhofer, A.; Brandner, R.; Schickhofer, G. 2015. Withdrawal resistance of self-tapping screws in unidirectional and orthogonal layered timber products. Mater Struct 48: 1435-1447. https://doi.org/10.1617/ s11527-013-0244-9

Schober, K.U.; Tannert, T. 2016. Hybrid connections for timber structures. European Journal of Wood and Wood Products 74(3): 369-377. https://doi.org/10.1007/s00107-016-1024-3

Smith, I.; Asiz, A.; Snow, M.; Chui, I. 2006. Possible Canadian/ISO approach to deriving design values from test data. In Proceedings of CIB Working Commission W18 - Timber, Florence, Italy.

Sullivan, K.; Miller, TH.; Gupta, R. 2018. Behaviour of cross-laminated timber diaphragm connections with self-tapping screws. Eng Struct 168: 505-524. https://doi.org/10.1016/j.engstruct.2018.04.094

Tannert, T. 2016. Improved performance of reinforced Rounded Dovetail Joints. Constr Build Mater 118: 262-267. https://doi.org/10.1016/j.conbuildmat.2016.05.038

Tannert, T.; Follesa, M.; Fragiacomo, M.; Gonzalez, P.; Isoda, H.; Moroder, D.; Xiong, H.; van de Lindt, J. 2018. Seismic design of cross-laminated timber buildings. Wood Fiber Sci 50: 3-26. https://wfs.swst. org/index.php/wfs/article/view/2720

Tannert, T.; Lam, F. 2009. Self-tapping screws as reinforcement for rounded dovetail connections. Structural Control and Health Monitoring 16(3): 374-384. https://doi.org/10.1002/stc.283

Tesfamariam, S.; Stiemer, SF; Dickof, C.; Bezabeh, M. 2014. Seismic vulnerability assessment of hybrid steel-timber structure: steel moment resisting frames with CLT infill. J Earthq Eng 18(6): 929-944. https://doi.org/10.1080/13632469.2014.916240

Tomasi, R.; Crosatti, A.; Piazza, M. 2010. Theoretical and experimental analysis of timber-to-timber joints connected with inclined screws. Constr Build Mater 24(9): 1560-1571. https://doi.org/10.1016/j.conbuildmat.2010.03.007

Tomasi, R.; Piazza, M.; Angeli, A.; Mores, M. 2006. A new ductile approach design of joints assembled with screw connectors. In Proceedings of World Conference on Timber Engineering, Portland, USA.

Vallée, T.; Tannert, T.; Meena, R.; Hehl, S. 2013. Dimensioning method for bolted, adhesively bonded, and hybrid joints. Compos Part B Eng 46: 179-187. https://doi.org/10.1016/j.compositesb.2012.09.074

Veilleux, L.; Gagnon, S.; Dagenais, C. 2019. Mass Timber Buildings up to 12 Storeys: Directives and Explanatory Guide. http://collections.banq.qc.ca

Weitzenboeck, J.R.; McGeorge, D. 2011. Science and Technology of Bolt-Adhesive Joints. In Hybrid Adhesive Joints. Springer, Berlin: Germany. 
Yeoh, D.; Fragiacomo, M.; De Franceschi, M.; Heng Boon, K. 2011. State of the art on timber-concrete composite structures. J Struct Eng-ASCE 137(10): 1085-1095. https://doi.org/10.1061/(ASCE)ST.1943$541 X .0000353$

Zhang, X.; Fairhurst, M.; Tannert, T. 2015. Ductility estimation for a novel timber-steel-hybrid system. J Struct Eng-ASCE 142(4): E4015001. https://doi.org/10.1061/(ASCE)ST.1943-541X.0001296

Zhang, X.; Tannert, T.; Popovski, M. 2018. High-capacity hold-down for tall timber buildings. Constr Build Mater 164: 688-703. https://doi.org/10.1016/j.conbuildmat.2018.01.019 